\title{
Music-dependent memory in immediate and delayed word recall
}

\author{
WILLIAM R. BALCH and KELLY BOWMAN \\ Pennsylvania State University, Altoona, Pennsylvania \\ and \\ LAURI A. MOHLER \\ Pennsylvania State University, University Park, Pennsylvania
}

\begin{abstract}
Undergraduate volunteers rated a series of words for pleasantness while hearing a particular background music. The subjects in Experiment 1 received, immediately or after a 48-h delay, an unexpected word-recall test in one of the following musical cue contexts: same cue (S), different cue (D), or no cue (N). For immediate recall, context dependency $(S-D)$ was significant but same-cue facilitation ( $\mathrm{S}-\mathrm{N}$ ) was not. No cue effects at all were found for delayed recall, and there was a significant interaction between cue and retention interval. A similar interaction was also found in Experiment 3, which was designed to rule out an alternative explanation with respect to distraction. When the different musical selection was changed specifically in either tempo or form (genre), only pieces having an altered tempo produced significantly lower immediate recall compared with the same pieces (Experiment 2). The results support a stimulus generalization view of music-dependent memory.
\end{abstract}

Music-dependent memory, of specific interest in the present study, is a case of context-dependent memory (CDM). The CDM principle was first proposed formally by McGeoch (1932), who called it "altered stimulus conditions." His hypothesis was that changing the context or environment in which material was originally learned causes some of that material to be forgotten. Godden and Baddeley (1975), using location as a context, provided the first clear evidence for CDM; more recently, locationdependent memory effects have been further supported (Smith, 1979; Smith, Glenberg, \& Bjork, 1978).

By now, CDM has been found for a variety of contexts in addition to location, including olfactory stimuli (Cann \& Ross, 1989; Schab, 1990), time of day (Holloway, 1978), alcohol or drug states (Eich, 1980; Eich, Weingartner, Stillman, \& Gillin, 1975; Weingartner, Adefris, Eich, \& Murphy, 1976), and hypnotically induced mood states (Bower, Monteiro, \& Gilligan, 1978; Lewis \& Williams, 1989). However, context-dependency effects have not always been obtained in recent studies. Failures to find reliable effects have been reported for mood-

\footnotetext{
Preparation of this article was supported in part by Faculty Development grants to the first author from Pennsylvania State University. We thank Paul Cornwell, who assisted us in our pilot research, provided some subjects from his classes for our experiments, and contributed useful comments and observations; Bob Elliott, who was also helpful in obtaining subjects and discussing the topic with us; John Jones and Lori Kimmel, who helped tabulate the data; and Steven Smith, Eric Eich, Robert Proctor, as well as an anonymous reviewer, for their helpful comments on an earlier version of this article. Requests for reprints should be sent to William R. Balch, Department of Psychology, Pennsylvania State University, Altoona, PA 16601.
}

dependent (Bower \& Mayer, 1989) and also for locationdependent (Fernandez \& Glenberg, 1985) memory.

Background music, the topic of the present paper, has recently been added to the list of contexts that have been found to affect memory (Smith, 1985). Smith presented his subjects with words in one of three different contexts: a jazz selection, a classical selection, or quiet (no music). Directly after presentation, an initial test was given-both to measure the degree of original learning and to make subjects think they would not have another recall test, so they would not rehearse the words for a second test 2 days later. For this delayed recall test, the context was either the same musical selection or one of the other two contexts (different selection or quiet). Either of these other contexts, in Smith's terminology, was defined as different. His results showed both context-dependent memory for delayed recall and a facilitative effect of providing the same context. As Smith stated, "context-dependent memory caused by background sound is the beneficial result of contextual cuing rather than a deleterious effect caused by the distraction of a new background during testing" (p. 591).

One issue addressed by the present research is the reliability of music-dependent memory, because so far, Smith's (1985) study appears to be the only one explicitly addressed to the phenomenon. Yet interestingly, music has recently been used as a method of influencing mood. These moodoriented studies have some bearing on the question of music-dependent memory. Eich and Metcalfe (1989) presented selections of happy or sad classical music, along with instructions to their subjects to think of something that would help them achieve the mood appropriate to the assigned music. During presentation, they were either 
read words or asked to generate words as examples of a given category. Again, 48-h delayed recall was tested, and a significant CDM effect was obtained for the read words. However, it was small: only a $3 \%$ advantage of the same over the different mood/music conditions. A larger effect $(9 \%)$ was obtained with words generated by the subjects themselves. This effect, however, could not be replicated by Bower and Mayer (1989). Given the above considerations, the present investigators wanted to see whether, and under what conditions, they could obtain music-dependent memory.

Another issue concerns the variable of retention interval. Smith (1985), as well as Eich and Metcalfe (1989), found their CDM effects by using delayed (48-h) retention. These effects make sense in light of the common observation that old songs bring back associated memories. To the knowledge of the present authors, however, no immediate recall test for music-dependent memory has been reported.

In the present study, CDM is tested for immediate as well as for delayed recall. There are, it should be noted, some good reasons to expect an effect for immediate recall. For instance, the location-dependent memory reported by Godden and Baddeley (1975) was obtained with only a 4-min retention interval. Moreover, Riccio, Richardson, and Ebner (1984), pointing out the logical similarity between CDM and the basic learning phenomenon of stimulus generalization, noted that the latter effect has been shown to decrease over time. If their view of CDM as a case of stimulus generalization is valid, music-dependent memory should interact with retention interval. Specifically, it should be larger for short than for long intervals. Accordingly, immediate and delayed recall were tested independently here in Experiment 1 by using different subjects under comparable conditions. In Experiment 3, the interaction between CDM and retention interval was again tested, this time with the explicit intention of eliminating distraction by the change in context as an alternative hypothesis.

Another point, addressed in Experiment 1, concerns the conclusion by Smith (1985) that providing the same musical context during both the presentation and recall of a word list serves as a facilitative retrieval cue. Whether context-dependency represents positive facilitation or simply a decrement in recall caused by changing contexts is a controversial question in the CDM literature. (See Rovee-Collier, Earley, \& Stafford, 1989, p. 149, for a recent discussion of this point.) To study this question, all of the subjects were presented with words while they listened to a musical selection. Then, during the test phase, different groups were asked to recall the words in one of three cue conditions: same (S), in which the musical selection was the same one used during original presentation; different (D), in which a different piece was heard for the recall test; and no $(\mathrm{N})$ cue, in which no music at all was played for the test (as in Smith's "quiet" recall condition). Facilitation, which indicates positive cuing caused by the same musical context, is defined here as the $\mathbf{S}-\mathbf{N}$ difference in number of words recalled. Inhibition, which shows the decrement in recall caused by a different musical context, is defined as D-N. Note that this effect is assumed to be specific to the recall of the word list and not to represent simple distraction-that is, a global disruption of concentration caused by changing the musical selection. (This assumption is tested in Experiment 3.) Finally, context dependency, defined as $S-D$, expresses the general influence of musical context on recall. All three of these effects are post hoc pairwise comparisons within the main effect of cue.

A final point addressed in this study relates to dimensions of musical difference. There appears to have been no previous attempt to identify which dimensions induce music-dependent memory and which do not. In Experiment 1 , the different musical selection played during the recall test was changed from the original one both in tempo (fast vs. slow or vice versa) and form (classical vs. jazz or vice versa). Thus, the intention in Experiment 1 was to maximize the contrast between same and different cue conditions in order to have the best chance of producing music-dependent memory. In Experiment 2, however, there were two types of different musical context cues: different tempo (DT) or different form (DF). Thus, two kinds of musical difference were tested separately for their contributions to the CDM effect. Finally, Experiment 3 was performed to provide evidence against interpreting the results of the preceding experiments in terms of a distraction artifact.

\section{EXPERIMENT 1}

Experiment 1 examined music-dependent memory in immediate and delayed recall. In this and subsequent experiments, an incidental memory procedure was used. Each word presented was rated for pleasantness, with a musical selection playing in the background. This rating procedure was deemed necessary to keep the procedure for immediate and delayed recall the same and to provide a decoy so that the subjects would not expect a memory test and rehearse the words. Recall in the present experiment was performed in the context of the same musical selection, a different musical selection, or no music.

\section{Method}

Subjects. The participants in this experiment were 240 students enrolled in introductory psychology classes at the Altoona and University Park campuses of Pennsylvania State University. Each experimental group consisted of equal numbers from each campus, and all subjects received a small amount of academic credit for serving in the study.

Materials. The word list used in all conditions of this experiment consisted of 24 common two- and three-syllable nouns, rated high in concreteness, taken from the norms of Spreen and Schulz (1966). All words were originally presented along with one of four background music selections: slow jazz (SJ), from an instrumental version of "How Long Has This Been Going On?" by F. Fox, B. Worth, and S. Cowan; fast jazz (FJ), from "Sing, Sing, Sing" 
by Benny Goodman; slow classical (SC), from the Clarinet Quintet in A Major by Mozart; and fast classical (FC), from "Devil's Trill" by Giuseppe Tartini.

The musical pieces were selected by the present authors as clear examples of a particular tempo (slow or fast) and form (jazz or classical). However, nouse of the pieces was judged likely to have been heard frequently by most of the subjects in the study. All selections were purely instrumental, with no vocals or lyrics. For each piece, an audio tape of 250 -sec duration was prepared, consisting of two repetitions of a 125 -sec excerpt.

Design. This experiment was designed to test the effect of musical cue-same (S), different (D), or no $(\mathrm{N})$ cue-on the immediate recall of words. Retention inierval-immediate or delayed (48 h)was a second independent variabie. The third, presentation context, consisted of four conditions. Each was based on a different musical selection (SJ, FJ, SC, or FC) that was played while the words were originally presented.

There were 10 different subjects in each of the 24 experimental groups. The $S$ groups, which received exactly the same musical selection for both presentation and recall contexts, can be designated as $\mathrm{SJ} / \mathrm{SJ}, \mathrm{FJ} / \mathrm{FJ}, \mathbf{S C} / \mathrm{SC}_{1}$ and FC/FC. The $\mathrm{D}$ groups, which received a different selection with respect to both tempo and form during recall, can be designated SJ/FC, FJ/SC, SC/FJ, and FC/SJ. Finally, the $\mathrm{N}$ groups, which received no music during recall, were $\mathrm{SJ} / \mathrm{N}, \mathrm{FJ} / \mathrm{N}, \mathrm{SC} / \mathrm{N}$, and $\mathrm{FC} / \mathrm{N}$.

Procedure. All subjects were run individually and were initially told that the purpose of the experiment was to rate words for pleasantness. Then they werc given a pencil and a bonklet for rating the words on a 6-point scale: 1 for very unpleasant. 2 for moderately unpleasant, 3 for slighty unpleasant, 4 for sightiy pleasant, 5 for moderately pleasant, and 6 for very pleasant. The subjects were told that background music would accompany the rating task to make it more enjoyable.

Words were typed separately on index cards for visual presentation. To help ensure sufficient exposure to the materials, two different random orders of the 24 words were run consecutively to produce the compete 48-word presentation sequence. The subjects were told in advance that each word would be repeated some where in the experimental sequence and that they should rate every word that came up according to their immediate impression of its pleasantness. Two different 48-word sequences were presented to half of the subjects in each group.

After the subjects had been instructed, the recording of the assigned musical selection was started. After $10 \mathrm{sec}$ of music, the experimenter began showing words at a rate of one word every $5 \mathrm{sec}$. The entire presentation took about $250 \mathrm{sec}$, after which the musical selection was stopped.

For the immediate-retention-interval groups, the rating booklets were then collected and the $\mathrm{S}, \mathrm{D}$, or $\mathrm{N}$ recall context was applied. The subjects were handed a blank sheet and asked to write down as many of the presented words as they could recall, in any order. The actual time elapsed between the presentation of the last word and the instruction to begin recall was about $30 \mathrm{sec}$. For the recall session, $4 \mathrm{~min}$ were allowed. Then the subjects were debriefed, both to inform them of the purpose of the study and to ask them to describe any particular strategies or memory proresses they might have been aware of during the experiment.

For the delayed-retention-interval groups, the subjects were told that they were finished with the current session. They were instructed that they would be asked to rate another set of words at a second session 2 days tater. This instruction was given so that the subjects would be unitikely to expect a memory test during the second session and therefore rehearse words on the presentataon list. When the subjects arrived for the second session, they were told that they would not have to perform another rating task. At this point, the experimenters followed the same recall-testing procedure that was used for the immediate retention interval.

\section{Results}

Overall analysis. To assess the effects of all three independent variables on immediate-recall scores, a $3 \times$ $2 \times 4$ (cue $\times$ retention interval $\times$ presentation context) independent-groups analysis of variance (ANOVA) was performed. Table 1 shows the means and standard deviations of these scores, based on a maximum of 24 words correctly recalled, for each of the 24 experimental groups.

Not surprisingly, the effect of retention interval was large and significant $\left[F(1,216)=482.32, M S_{e}=6.78\right]$ (the $.05 p$-value criterion was used). For immediate recall, the subjects remembered an average of 13.03 words. After a 48-h delay, however, recall dropped to an average of only 5.64 words.

The only other significant effect was the cue $\times$ retention interval interaction $\left[F(2,216)=4.65, M S_{e}=6.78\right]$. This interaction indicates that the effect of cue on word recall depended critically on the retention interval. To assess the difference in the effects, separate analyses were performed for each retention interval.

Immediate recall. A $3 \times 4$ (cue $\times$ presentation context) independent-groups ANOVA was performed on the recall scores of the 12 immediate-recall groups. For this immediate retention interval, the subjects receiving the same musical cue performed best, recalling a mean of 13.85 words. The different groups showed the poorest performance, averaging 12.15 words recalled. For the nocue subjects, the performance fell between the levels of the $S$ and $D$ groups, averaging 13.08 words recalled. The main effect of cue was significant $\left[F(2,108)=3.59, M S_{e}\right.$ $=8.06]$. Yet neither the presentation context (SJ, FJ, SC, or FC) nor cue $\times$ presentation context effects were significant $\left(F_{\mathrm{S}}<1\right)$.

To test the pairwise comparisons between the three cue conditions, Scheffé post hoc tests were performed. This procedure revealed that context dependency $(S-D)$ was significant. However, same-cue facilitation $(S-N)$ and different-cue inhibition $(D-N)$ were not significant. Though nonsignificant in themselves, both the facilitative $(S-N)$ and inhibitory $(D-N)$ effects were in the ap-

Table 1 Recall Scores for Experiment 1

\begin{tabular}{|c|c|c|c|c|c|c|}
\hline \multirow{3}{*}{$\begin{array}{c}\text { Presentation } \\
\text { Contex: }\end{array}$} & \multicolumn{6}{|c|}{ Cue } \\
\hline & \multicolumn{2}{|c|}{ Same Cue } & \multicolumn{2}{|c|}{ Different Cue } & \multicolumn{2}{|c|}{ No Cue } \\
\hline & $M$ & $S D$ & $M$ & $S D$ & $M$ & $S D$ \\
\hline \multicolumn{7}{|c|}{ Immediate Recall } \\
\hline Slow jazz & 14.0 & 3.6 & 11.9 & 3.1 & 13.4 & 2.7 \\
\hline Fast jazz & 13.8 & 2.2 & 12.1 & 2.6 & 13.4 & 2.4 \\
\hline Slow classical & 13.4 & 3.4 & 13.5 & 2.3 & 13.4 & 3.5 \\
\hline Fast classical & 14.2 & 2.5 & 11.1 & 3.0 & 12.1 & 2.3 \\
\hline \multicolumn{7}{|c|}{ Delayed Recall } \\
\hline Slow jazz & 5.8 & 2.3 & 6.9 & 2.4 & 6.4 & 2.6 \\
\hline Fast jazz & 5.3 & 2.7 & 5.5 & 2.2 & 5.3 & 1.6 \\
\hline Slow classical & 5.1 & 2.4 & 5.6 & 1.8 & 5.9 & 2.0 \\
\hline Fast classical & 5.4 & 2.8 & 5.9 & 2.8 & 5.7 & 2.5 \\
\hline
\end{tabular}

Note-Entries are $M$ and $S D$ of numbers of words recalled out of 24 $(n=10$ for each entry). 
propriate directions (positive and negative, respectively). Accordingly, a check on the linear trend of the three ordered means (D, N, and S) was performed. Linear trend was significant $\left[F(1,108)=7.17, M S_{\mathrm{e}}=8.06\right]$. This result suggests that facilitation and inhibition contributed jointly to the cue effect.

Delayed recall. A $3 \times 4$ (cue $\times$ presentation context) independent-groups ANOVA was performed on the recall scores of the 12 delayed $(48 \mathrm{~h}$ ) retention groups. For this delayed interval, the $\mathrm{S}, \mathrm{D}$, and $\mathrm{N}$ groups averaged 5.15 , 5.95 , and 5.83 words recalled, respectively, out of 24 . Although this time the performance of the same-cue condition was, surprisingly, the lowest of the three cue conditions, there was no significant effect of cue $[F(2,108)$ $=1.35, M S_{\mathrm{e}}=5.50 \mathrm{]}$. Neither presentation context $(\mathrm{SJ}$, FJ, SC, FC) nor cue $\times$ presentation context was significant $(F \mathrm{~s}<1)$.

During debriefing sessions, the experimenters checked to make sure the subjects had not expected a delayedmemory test. If they had, they might have rehearsed words during the 2-day retention interval. Such a problem could have decreased or eliminated a CDM effect. However, when asked during debriefing, no subjects indicated that they had anticipated the recall test. Instead, they reported that they had expected to perform another rating task, as the experimenter had led them to believe. Therefore, the absence of a music-dependent memory effect in delayed recall is unlikely to have stemmed from rehearsal of the words during the retention interval.

\section{Discussion}

The results of Experiment 1, together with the findings of Smith (1985) and Eich and Metcalfe (1989), provide a body of evidence that music is an effective stimulus for inducing context-dependent memory. However, there are points of difference between the music-dependent memory found here and the results of the previous studies.

One difference is that the present results were obtained for immediate recall, that is, recall tested shortly (about $20 \mathrm{sec}$ in this case) after initial presentation of the word list. On the other hand, both Smith (1985) and Eich and Metcalfe (1989) obtained CDM with 48-h delayed recall. Thus, this experiment appears to be the first to demonstrate the effect with immediate recall.

Another difference is that there was no evidence for a sufficient facilitation effect $(S-N)$, though significant context dependency (S - D) was found for immediate recall. In other words, providing the same musical selection during recall did not cause the subjects to remember significantly more words than providing no music at all. Though Smith (1985) did find evidence for sufficient same-cue facilitation, the present results are at least in the direction of a facilitative effect. Since the $\mathrm{N}$ mean fell between the $S$ and $D$ means and the linear trend was significant, the context-dependency effect found here appears to arise from the combined influence of facilitation $(S-N)$ caused by the same musical cue and inhibition $(D-N)$ caused by the different cue. An alternative explanation is that the results were due entirely to simple distraction and that the general disruption in the subjects' concentration on the recall task was due to a quick change in contexts. This possible account will be addressed in Experiment 3.

Unlike the findings of two previous studies (Eich \& Metcalfe, 1989; Smith, 1985), the present results show a failure to obtain music-dependent memory for the recall of a word list after 2 days. This discrepancy will be elaborated on later, in the General Discussion section. The emphasis of the present report, however, is on the cue $x$ retention interval interaction obtained here rather than on the lack of a cue effect in delayed recall. Using the same procedures and cue conditions for both immediate and delayed retention intervals, CDM was obtained only for immediate recall. The influence of retention interval on CDM is theoretically interesting and seems to be best explained in terms of the Riccio et al. (1984) view of CDM as a stimulus generalization gradient.

Applying this viewpoint, the significant S-D comparison-found here in immediate recall-is like the contrast between two test stimuli, one of which is identical to the training stimulus and one of which differs along a continuum. The continuum in this case refers to some dimension or dimensions of musical difference between the selections used in this study. Since generalization gradients tend to flatten over time (Riccio et al., 1984), CDM effects should likewise diminish as the retention interval increases. Thus, the cue $x$ retention interval interaction obtained here is consistent with a stimulus-generalization view of $\mathrm{CDM}$, in which the gradient flattens over time as the inducing stimuli become functionally more interchangeable.

\section{EXPERIMENT 2}

The analogy between music-dependent memory and a generalization gradient would be made stronger if evidence were obtained for specific dimensions of musical difference. In Experiment 1, the different musical cue was changed in both tempo and form from the original presentation cue. In Experiment 2, there were two different cues, one based just on tempo and the other just on form. Each was compared with the same-cue condition.

Since CDM was found only for immediate recall in Experiment 1 , only the immediate retention interval was used in Experiment 2. Obtaining a context-dependency effect (S - D) for tempo and/or form would reinforce the conclusion of Experiment 1 that musical stimuli can induce CDM for immediate recall. The results should also help specify which musical dimensions are important in producing the effect.

\section{Method}

Subjects. The participants were 120 introductory psychology students at Pennsylvania State University, with equal numbers from the Altoona and University Park campuses. None had participated in the first experiment.

Materials, Design, and Procedure. The methodology was identical to that employed in the immediate recall groups of Experiment 1, except for the cue conditions used. In Experiment 2, there were two conditions in which the cue was different. 
The different-tempo (DT) condition was based on a change of tempo (slow to fast or vice versa) but not a change of form. The four DT groups were thus SJ/FJ, FJ/SJ, SC/FC, and FC/SC.

During recall, the different-form (DF) groups received a selection having a changed form (jazz to classical or vice versa) but not a changed tempo. The four DF groups, then, were SJ/SC, FJ/FC $\mathrm{SC} / \mathrm{SJ}$, and $\mathrm{FC} / \mathrm{FJ}$.

As in Experiment I, there were 4 same-cue (S) groups, SJ/SJ, FJ/FJ, SC/SC, and FC/FC. There was not, however, a no-cue condition in this experiment.

\section{Results}

The means and standard deviations of all 12 groups are shown in Table 2. Note that the same-cue groups scored highest in recall, with an average of 14.1 words out of a possible 24 . The different-tempo groups showed the poorest performance, averaging only 12.03 words; the different-form groups recalled a mean of 13.2 words.

A $3 \times 4$ (cue $\times$ presentation context) independentgroups ANOVA was performed on the recall scores. The main effect of cue was significant $\left[F(2,108)=7.06, M S_{e}\right.$ $=6.14]$. However, neither the presentation context effect nor the cue $\times$ presentation context interaction was significant $(F \mathrm{~s}<1)$.

To evaluate the pairwise comparisons between the three cue conditions, Scheffé post hoc tests were performed. The S - DT difference, indicating the effect of changing musical context with respect to tempo, was significant. However, neither of the other comparisons (S - DF and DF - DT) was significant.

\section{Discussion}

The results of Experiment 2 show that tempo is a more important dimension of musical difference than form (i.e., genre) with respect to its ability to induce contextdependent memory. Changing to a selection of a different tempo, even if the form (classical or jazz) was not changed, yielded significantly lower recall (about 9\%) than did playing the same piece during recall. Yet changing to a piece of a different form but a comparable tempo was statistically equivalent (only a $4 \%$ difference) to choosing the same selection. Of course, tempo and form changes may not have been equally discriminable to the subjects. During debriefing, however, the subjects in both the DT and DF conditions were asked whether or not the selection played during recall was the same piece they had

Table 2

Immediate Recall Scores for Experiment 2

\begin{tabular}{|c|c|c|c|c|c|c|}
\hline \multirow{3}{*}{$\begin{array}{l}\text { Presentation } \\
\text { Context }\end{array}$} & \multicolumn{6}{|c|}{ Cue } \\
\hline & \multicolumn{2}{|c|}{ Same Cue } & \multicolumn{2}{|c|}{ Different Tempo } & \multicolumn{2}{|c|}{ Different Form } \\
\hline & $M$ & $S D$ & $M$ & $S D$ & $M$ & $S D$ \\
\hline Slow jazz & 13.6 & 2.6 & 11.6 & 2.4 & 13.2 & 2.0 \\
\hline Fast jazz & 14.7 & 3.4 & 11.7 & 2.7 & 12.6 & 3.0 \\
\hline Slow classical & 14.5 & 1.9 & 13.0 & 3.1 & 13.8 & 1.8 \\
\hline Fast classical & 13.6 & 1.8 & 11.8 & 1.8 & 13.2 & 2.5 \\
\hline
\end{tabular}

Note-Entries are $M$ and $S D$ of numbers of words recalled out of 24 $(n=10$ for each entry). heard while they were performing the pleasantness ratings. In each condition, 34 out of 40 correctly answered that the selections were different. This observation at least suggests that the effectiveness of tempo, rather than form, differences in producing the CDM effect cannot be explained in terms of simple discriminability between two musical selections.

Note that there may well be other dimensions of musical change, besides tempo, that demonstrably affect memory. The sample of four selections used here was small. Furthermore, only two dimensions of difference were investigated.

Despite these limitations in musical scope, the results of Experiment 2 reinforce the notion of music-dependent memory as a stimulus generalization gradient (Riccio et al., 1984). Such a gradient is always defined with respect to a particular continuum. It follows that musicdependent memory should be producible by isolating specific dimensions of musical difference and varying context according to those dimensions. Furthermore, the different selection must vary from the original one along an effective continuum: tempo, in this case, but not form. Merely selecting a different piece of background music, then, is not sufficient to produce a significant CDM effect.

\section{EXPERIMENT 3}

The stimulus generalization view of music-dependent memory would be further strengthened by addressing the problem of possible distraction effects caused by the present methodology. Effects of CDM have been found here for the immediate retention interval $(S-D$ in Experiment 1, immediate recall, and S-DT in Experiment 2) but not for the delayed interval (no cue effect in Experiment 1, delayed recall). So far, this influence of retention interval could possibly be explained by a simple distraction phenomenon. Consider that in immediate recall a quick change from one musical selection to another could potentially disrupt subjects' attention to any task that they might be required to perform. Therefore, the significant S-D and S - DT effects, obtained for the immediate retention interval, might have stemmed from the distraction involved in a musical change rather than from contextual influences on memory per se. Such distraction would be less likely for delayed recall, since the musical change occurs after a 2 -day period. Thus, the cue $x$ retention interval interaction found in Experiment 1 might simply arise from the differential distraction of different (vs. same) musical selections when the change in context is quick, as in immediate recall.

In Experiment 3, as in Experiment 1, CDM was tested at both the immediate and delayed retention intervals. Experiment 3 , however, featured a technique similar to the "disrupted" condition that Godden and Baddeley (1975) used (p. 329) to rule out the hypothesis of distraction. Following their general approach, all subjects in Experiment 3 were intentionally distracted directly after the 
presentation of the words. Thus, any subsequent effect of cue on recall should reflect an influence of context on memory per se.

\section{Method}

Subjects. The participants were 80 introductory psychology students at Pennsylvania State University, with equal numbers from the Altoona and University Park campuses. None had participated in the first two experiments.

Materials, Design, and Procedure. The methodology was similar to that of Experiment 1, except that a "distraction" piece, lasting $30 \mathrm{sec}$, was played just before the subjects were given the recall task in the assigned musical-cue context. The distraction music was an excerpt from a piece called "Haegum Shinawa," featuring a solo two-stringed Korean violin. The selection, an example of Korean P'ansori music, was essentially atonal and was intended to sound unusual, distracting, and as different as possible from the Western musical conventions of the pieces played during presentation.

Note that the introduction of the distraction piece slightly lengthened the immediate retention interval, compared with the interval used in Experiments 1 and 2, to about $1 \mathrm{~min}$. For the delayedinterval groups, the distraction piece was played at the start of the second session. Directly afterward, the musical selection assigned for the recall task was started. The subjects were then given a sheet of paper and instructed, similarly to the immediate retention groups, to write down the words they had rated during presentation.

Since, in the first two experiments, presentation context neither was significant as a main effect nor was involved in any interactions, only two conditions were included this time: fast jazz and slow jazz. The classical selections were dropped for an additional reason. Both selections included string instruments in the orchestration and might not have contrasted sharply enough with the distraction piece.

The cue variable involved two conditions: same (S), consisting here of FJ/FJ and SF/SJ groups, and the different-tempo (DT) condition of Experiment 2, consisting here of the FJ/SJ and SJ/FJ groups. It should be noted that changing to the selection of a different tempo in Experiment 2 was found to be sufficient for producing CDM.

\section{Results and Discussion}

Overall analysis. First, a $2 \times 2 \times 2$ (cue $\times$ retention interval $\times$ presentation context) independent-groups ANOVA was performed on the memory scores, with 10 subjects in each of the eight groups. Table 3 shows the means and standard deviations for each of these groups.

As expected, retention interval had a significant effect on recall $\left[F(1,72)=205.01, M S_{\mathrm{c}}=5.13\right]$. For the im-

Table 3

Recall Scores for Experiment 3

\begin{tabular}{|c|c|c|c|c|}
\hline \multirow{3}{*}{$\begin{array}{c}\text { Presentation } \\
\text { Context }\end{array}$} & \multicolumn{4}{|c|}{ Cue } \\
\hline & \multicolumn{2}{|c|}{ Same Cue } & \multicolumn{2}{|c|}{ Different Tempo } \\
\hline & $M$ & $S D$ & $M$ & $S D$ \\
\hline \multicolumn{5}{|c|}{ Immediate Recall } \\
\hline Slow jazz & 13.8 & 2.8 & 11.0 & $\begin{array}{l}2.7 \\
1.9\end{array}$ \\
\hline \multicolumn{5}{|c|}{ Delayed Recall } \\
\hline $\begin{array}{l}\text { Slow jazz } \\
\text { Fast jazz }\end{array}$ & $\begin{array}{l}5.2 \\
5.1\end{array}$ & $\begin{array}{l}2.1 \\
2.2\end{array}$ & $\begin{array}{l}6.9 \\
4.8\end{array}$ & $\begin{array}{l}1.7 \\
1.4\end{array}$ \\
\hline
\end{tabular}

Note-Entries are $M$ and $S D$ of numbers of words recalled out of 24 ( $n=10$ for each entry). mediate retention interval, the subjects remembered an average of 12.27 words. For delayed recall, however, the subjects' performance dropped to an average of only 5.5 words.

Of particular interest here is the significant cue $\times$ retention interval interaction $\left[F(1,72)=6.05, M S_{e}=5.13\right]$. This interaction arises because for immediate, but not for delayed recall, the $S$ groups recalled more words than did the DT groups. To further assess this interaction, separate analyses were performed for each retention interval.

Immediate recall. A $2 \times 2$ (cue $\times$ presentation context) independent-groups ANOVA was performed on the recall scores of the four immediate recall groups, shown in the top half of Table 3. Presentation context did not significantly affect word recall $\left[F(1,36)=1.80, M S_{e}=\right.$ $6.71]$, nor did the cue $\times$ presentation context interaction $\left[F(1,36)=2.66, M S_{\mathrm{e}}=6.71\right]$.

Cue did significantly affect recall $\left[F(1,36)=4.83, M S_{\text {e }}\right.$ $=6.71]$. S groups recalled an average of 13.65 words, whereas DT groups recalled a mean of only 11.85 . As in both Experiments 1 and 2, there was again evidence of context-dependent memory for immediate recall. In the present experiment, though, all subjects heard a 30-sec distraction piece just prior to recall. Thus, the DT groups were unlikely to have recalled fewer words than the $S$ groups because they were more distracted by the change in musical selection.

Delayed recall. A $2 \times 2$ (cue $\times$ presentation context) independent-groups ANOVA was performed on the recall scores of the four delayed-recall groups, shown in the bottom half of Table 3. Note that all groups remembered an average of about 5 words, except for the DT group receiving the SJ presentation context. These subjects received the slow jazz selection during presentation and fast jazz during the recall task, and remembered an average of 6.9 words. It is not clear why this group performed better than the others, and for delayed recall only, but as a result, there were near-significant effects $(p<.10)$ of presentation context $\left[F(1,36)=3.80, M S_{\mathrm{e}}=3.55\right]$ and of the cue $\times$ presentation context interaction $[F(1,36)=3.62$, $M S_{\mathrm{e}}=3.55$.

There was no effect of cue on recall after $48 \mathrm{~h}[F(1,36)$ $\left.=1.38, M S_{\mathrm{c}}=3.55\right]$. Groups receiving the $\mathrm{S}$ musical cue averaged 5.15 words recalled, whereas those receiving the DT cue averaged 5.85 words. Although the procedure used with delayed-interval subjects was equivalent to that used with their immediate-interval counterparts, note that context-dependent memory was found here only for the latter subjects.

\section{GENERAL DISCUSSION}

The results of the present experiments are in general agreement with Smith's (1985) conclusion that background music can be used to induce context-dependent memory. For the immediate retention interval, moderately superior recall was shown here by the same-cue subjects. The S - D difference was about 7\% in Experiment 1 for 
the immediate-recall groups. Likewise, the S - DT difference was about $9 \%$ in Experiment 2 and about $8 \%$ in Experiment 3 for the immediate-recall groups. Together with the findings of previous studies (Eich \& Metcalfe, 1989; Smith, 1985), these results show that music-dependent memory is basically a reliable phenomenon.

A key difference between the present work and the earlier work concerns the issue of retention interval. Previous reports (Eich \& Metcalfe, 1989; Smith, 1985) tested music-dependent memory for only delayed recall and found significant CDM effects. In the present study, no CDM effect was found under conditions of delayed recall. There are, however, some key features of the present methodology that might have contributed to the absence of a CDM effect in delayed recall. First, the present subjects were not required to generate the words to be remembered, in any way, before the recall test itself. Eich and Metcalfe (1989) obtained a small CDM effect $(3 \%)$ when the words to be remembered were presented to, rather than generated by, the subjects. Smith (1985) obtained a much larger effect (about 20\%) with presented words. However, Smith's subjects were given an initial free-recall test, in the same context in which the words to be remembered had just been presented. By recalling the words initially, the subjects were, in effect, generating them in context. Note that Eich and Metcalfe (1989) obtained a larger CDM (9\%) effect when subjects generated words by category, compared with their $3 \%$ effect with presented words. Yet in the present methodology, although an incidental pleasantness rating task was used, the subjects were not required to generate the words except during recall.

In addition, the pleasantness rating procedure used here may have contributed to the absence of CDM for delayed recall. This procedure was employed to measure both immediate and delayed recall under the same procedure, without having the subjects in either condition expect a memory test. However, the pleasantness ratings may have served as an additional context during the word-presentation phase. Since no reference to the ratings was made during the recall phase, all of the conditions involved a shift in this one aspect of context. This shift may have adversely affected recall and reduced the CDM effect in the more difficult delayed-retention-interval task.

Thus, the incidental rating task used here, and also the absence of an initial memory test in the same musical context, may have contributed to the present results. The discrepancy between the long-term CDM effects found by Smith (1985) and by Eich and Metcalfe (1989) and the lack of such an effect found here needs to be clarified and resolved through further research. Meanwhile, of most importance in the present study is the assessment, under equivalent procedures, of the CDM effect for both immediate and delayed recall. The major finding in this regard was a reliable cue $x$ retention interval interaction. This interaction was obtained in Experiment 1 and again in Experiment 3, with the potential for distraction made comparable across cue conditions in the latter case. In both cases, CDM was found for immediate but not for delayed recall.

The cue $x$ retention interval interaction obtained here is consistent with the stimulus generalization view of CDM (Riccio et al., 1984). Since generalization gradients flatten over time, different musical selections should become more functionally equivalent over time. Thus, the shorter the retention interval, the larger the music-dependent memory effect should be. Note that the stimulus generalization analogy requires only obtaining a larger effect for a short interval and does not necessitate finding no effect for delayed intervals.

The stimulus generalization view is supported in another way by the results of Experiment 2, which investigated the effects on immediate recall of changing two different musical dimensions. Only the subjects who heard a selection having a different tempo recalled significantly fewer words than did the subjects who heard the same piece. Selections having a different form but an equivalent tempo did not produce significantly lower recall than did the same selections. Musical background, then, must be changed along an effective musical dimension for CDM to occur.

In Experiment 3, a CDM effect was obtained for immediate recall when all of the subjects heard an intentionally distracting piece of music. This piece was played for $30 \mathrm{sec}$ just before the start of the recall task. Therefore, the subjects receiving the same musical selection during recall were unlikely to have been less distracted than those receiving a different selection. The cue variable thus appears to have influenced memory for the presented words but not the amount of general disruption to the subjects.

Note that this effect of musical context on memory is not explained here only by cue facilitation. Comparisons were performed in Experiment 1 between the same (S), different (D), and no-cue (N) conditions. These comparisons, together with a linear trend analysis, indicated that facilitation by the same context $(\mathrm{S}-\mathrm{N})$ and inhibition by the different context $(D-N)$ acted in combination to produce music-dependent memory. A similar result was found for olfactory stimuli by Cann and Ross (1989).

In explaining CDM, an alternative to stimulus generalization is the encoding specificity principle. Kihlstrom (1989), in a review of mood-dependent memory studies, summarized this view as follows:

In whatever form it occurs, such context dependency in memory is predicted by the encoding specificity principle (Tulving \& Thomson, 1973), which states that the accessibility of a memory is determined by the degree of similarity between the information encoded at the time an event occurred and that supplied at the time of retrieval. The environmental and organismic contexts apparently supply some of this information. (p. 27)

Like the stimulus generalization view, the encoding specificity principle predicts CDM, but it appears to make the additional assumption that the same context serves as 
a facilitative recall cue. In the present study, however, an inhibitory effect on memory caused by a change of context may also have contributed to music-dependent memory (Experiment 1). Moreover, the CDM effect was influenced both by retention interval (Experiments 1 and 3 ) and by the type of musical change involved in defining a different context (Experiment 2). The memory effects obtained in this study seem best explained by a musical contrast between two selections-in other words, a generalization gradient.

Though the possible influence of retention interval on CDM has been discussed theoretically by Riccio et al. (1984), this issue has not been addressed empirically before the present study. It is to be hoped that more CDM studies employing both short and long retention intervals will be performed in the future. Only then can the utility of stimulus generalization as an explanatory mechanism for CDM be fully assessed.

A final observation concerns the relation between the present results and everyday examples of music-related memory. Although CDM was found here only for immediate recall, it is a common experience that old songs bring back memories (Smith, 1985). This example seems to demonstrate both long-term CDM and facilitative cuing. Furthermore, one of the present authors has had experiences with such examples. For instance, he recently heard a certain "oldie but goody" on the radio. He could recall exactly on which street and in which city he was driving, and in which car, when he first heard the song played years ago.

There are, of course, many influences at work in such examples that do not typically apply in laboratory studies, including the presence of lyrics, the often-repeated associations which sometimes occur between musical context and the material to be remembered, and the special meaningfulness that might apply to the musical context or to the associated material. The present authors still accept the plausibility of long-term musical cuing, despite the lack of evidence for it in the present study.

\section{REFERENCES}

BOWER, G. H., \& MAYER, J. D. (1989). In search of mood dependent retrieval. Journal of Social Behavior \& Personality, 4, 121-156. Bower, G. H., Monteiro, K. P., \&illigan, S. G. (1978). Emo- tional mood as a context for learning and recall. Joumal of Verbal Learning \& Verbal Behavior, 14, 408-417.

CANN, A., Ross, D. A. (1989). Olfactory stimuli as context cues in human memory. American Joumal of Psychology, 2, 91-102.

EICH, E., \& MetCALFE, J. (1989). Mood-dependent memory for internal versus external events. Joumal of Experimental Psychology: Learning, Memory, \& Cognition, 15, 433-455.

EICH, J. E. (1980). The cue-dependent nature of state-dependent retrieval. Memory \& Cognition, 8, 157-173.

Eich, J. E., Weingartner, H., Stillman, R., Gillin, J. (1975). State-dependent accessibility of cues and retention of a categorized list. Joumal of Verbal Learning \& Verbal Behavior, 14, 408-417.

FerNandez, A., GlenberG, A. M. (1985). Changing environmental context does not reliably affect memory. Memory \& Cognition, 13, 333-345.

GodDen, D. R., \& BADDELEY, A. D. (1975). Context-dependent memory in two natural environments: On land and underwater. British Journal of Psychology, 66, 325-331.

HollowAY, F. A. (1978). State-dependent retrieval based on time of day. In B. T. Ho, D. W. Richards III, \& D. L. Chute (Eds.), Drug discrimination and state-dependent leaming (pp. 319-343). New York: Academic Press.

KlHLSTRom, J. F. (1989). On what does mood-dependent memory depend? Journal of Social Behavior \& Personality, 4, 23-32.

LEWT, V. E., WILLIAMS, R. N. (1989). Mood-congruent vs. moodstate dependent learning: Implications for a view of emotion. Journal of Social Behavior \& Personality, 4, 157-171.

MCGeOCH, J. A. (1932). Forgetting and the law of disuse. Psychological Review, 39, 352-370.

Riccio, D. C., Richardion, R., \& Ebner, D. L. (1984). Memory retrieval deficits based upon altered contextual cues: A paradox. Psychological Bulletin, 96, 152-165.

Rovee-Collier, C., EArley, L., \& Stafford, S. (1989). Ontogeny of early event memory: III. Attentional determinants of retrieval at 2 and 3 months. Infant Behavior \& Development, 12, 147-161.

SCHAB, F. R. (1990). Odors and the remembrance of things past. Journal of Experimental Psychology: Leaming, Memory, \& Cognition, 16, 648-655.

SMITH, S. M. (1979). Remembering in and out of context. Journal of Experimental Psychology: Human Learning \& Memory, 5, 460-471.

SMITH, S. M. (1985). Background music and context-dependent memory. American Journal of Psychology, 6, 591-603.

Smith, S. M., Glenderg, A., \& BJork, R. A. (1978). Environmental context and human memory. Memory \& Cognition, 6, 342-353.

SPREEN, O., Schulz, R. W. (1966). Parameters of abstraction, meaningfulness and pronunciability for 329 nouns. Journal of Verbal Leaming \& Verbal Behavior, 5, 459-468.

Tulving, E., Thomson, D. (1973). Encoding specificity and retrieval processes in episodic memory. Psychological Review, 80, 352-373.

Weingartner, H., Adefris, W., Eich, J. E., \& MURPHY, D. L. (1976). Encoding imagery specificity in alcohol state-dependent learning. Journal of Experimental Psychology, 2, 83-87.

(Manuscript received September 27, 1990; revision accepted for publication June 26, 1991.) 